\title{
Nutrient intakes during pregnancy: the influence of smoking status and age
}

\author{
Fiona Mathews, Patricia Yudkin, Robert F Smith, Andrew Neil
}

\begin{abstract}
Study objective-To examine the relation of antioxidant and other nutrient intakes in pregnancy to smoking and sociodemographic variables.

Design-Cohort study.

Setting-St Mary's Maternity Hospital, Portsmouth.

Participants-Pregnant nulliparous women, with no existing complications of pregnancy, were recruited from antenatal booking clinics. A total of 774 women completed seven day food diaries, and supplied detailed data on their use of nutrient supplements.

Main results-Smokers had lower intakes of most micronutrients. After adjustment for the confounding effects of maternal age, height, and education, only vitamin $C$ and carotenoid intakes remained significantly depressed. Age was strongly and significantly associated with the intake of most nutrients, including antioxidants, and this association was independent of other maternal factors. Antioxidant intake was therefore lowest in young women who smoked: for example smokers under 24 years had a mean vitamin $C$ intake of 57 mg (SD 35) compared with $106 \mathrm{mg}$ (SD 52) for non-smokers aged 28 and over (difference $49 \mathrm{mg}, 95 \%$ CI 39, 59). The corresponding intakes of carotenoid equivalents were $1335 \mu \mathrm{g}$ (SD 982) and $2093 \mu \mathrm{g}$ (SD 1283) (difference $758 \mu \mathrm{g}, 95 \%$ CI 496, 1020). Conclusions-The study has identified, for the first time, young pregnant women as a group at particular risk of low micronutrient intake. The health implications of poor nutrition now need to be evaluated, particularly for those women who smoke. (F Epidemiol Community Health 2000;54:17-23)
\end{abstract}

Division of Public Health and Primary Health Care, Institute of Health Sciences, University of Oxford, Oxford

F Mathews

$P$ Yudkin

A Neil

Division of Biomedical Science, Sheffield Hallam University, Sheffield

R F Smith

Correspondence to: Fiona Mathews, Department of Zoology, University of Oxford, South Parks Road, Oxford, OX2 6PS

Accepted for publication 24 May 1999 intakes. ${ }^{16}{ }^{17}$ This may result from high free radical load exposure, and the utilisation of antioxidants in smoke detoxification. The diets of smokers are generally poorer than non-smokers. ${ }^{18-25}$ Given that smokers are at increased risk of oxidative tissue damage, ${ }^{26} \mathrm{a}$ poor dietary intake of antioxidant nutrients may be particularly important. Yet few studies have used methods sufficiently precise and reliable to give good estimates of micronutrient intakes, ${ }^{182227}$ and none has investigated the use of nutrient supplements, or confirmed self reported smoking status using a biochemical marker. There has also been little exploration of other factors that might influence micronutrient intakes, such as education and age, either in the general population or in pregnant women. The two available studies considering age in pregnancy suggest that very young girls in the USA are at risk of poor intakes of several nutrients including iron, calcium and folate. ${ }^{28} 29$

There is evidence that some micronutrients may be important to pregnancy outcome..$^{30-32}$ It has also recently been suggested that chronic adult diseases can be "programmed" during fetal growth. ${ }^{33}$ We have therefore investigated the dietary intake of large cohort of randomly selected pregnant women. Only nulliparous women were included to allow the effects of factors such as age and education to be separated from those of parity. Particular attention has been paid to smoking status and other sociodemographic factors, which, it has been suggested, may confound the relation between poor maternal diet and compromised fetal growth. ${ }^{34}$

\section{Methods}

SUBJECTS

Full details of the survey methodology have been reported elsewhere..$^{35}$ Briefly, recruitment of subjects took place from May 1994 to February 1996 inclusive, with ethical committee approval. Based on sample size calculations relating to the main purpose of the study (the detection of differences in mean birth weight between women with high and low intakes of antioxidant nutrients), 1002 pregnant white nulliparous women were invited to take part in the study. Random sampling, stratified by smoking status, was used to select subjects from the seven largest antenatal booking clinics held each week at St Mary's Hospital, Portsmouth, and its annexes. All women in this district, except those planning a home delivery, were referred to central antenatal clinics for booking. The sampling procedure resulted in the proportion of self reported smokers in our cohort being similar to that of nationally 
representative samples of pregnant women. ${ }^{89}$ Only women with no existing chronic diseases, no poor obstetric history, and no antenatal complications of pregnancy were invited to participate. At the time of interview $90 \%$ of the subjects were between 14 and 17 completed weeks gestation, and all were between 9 and 20 weeks. Gestational ages were best estimates derived from an algorithm that included ultrasound scan data and last menstrual period dates (details available on request).

SOCIODEMOGRAPHIC DATA

Structured interviews with subjects were conducted during the booking clinics by three trained researchers to gather information on socioeconomic status, smoking habits, and education. Social class was based on the occupation of the woman or her partnerwhichever gave the highest social classaccording to the Registrar General's classification. ${ }^{36}$ Members of the armed forces were assigned the social class of the equivalent civilian occupation. Heights, weights, and blood pressures were those measured routinely by the midwife at the booking clinic.

During the blood test at antenatal booking, additional samples were taken and the serum stored at $-70^{\circ} \mathrm{C}$. The cotinine concentration of the samples was determined using established radioimmunoassay methods. ${ }^{37}$ Women were classified as "smokers" if they reported smoking at least one cigarette on the day before interview, or that they usually smoked more than one cigarette per day, or if they had a serum cotinine concentration greater than 14 $\mathrm{ng} / \mathrm{ml}$. The cut off point for serum cotinine is based on the work of Cummings et $a l^{\beta 8}$ and has been used previously ${ }^{39}{ }^{40}$; it is less likely to misclassify non-smokers as smokers than the 10 $\mathrm{ng} / \mathrm{ml}$ cut off used by others. ${ }^{41}{ }^{42}$

\section{DIETARY ASSESSMENT}

Subjects recorded, with estimated portion sizes, all foods, drinks and nutrient supplements consumed in the seven days after the interview. A demonstration of how to complete the diary (a modified version of that used in the European Prospective Investigation of Cancer, EPIC) was given by the interviewer at booking. This type of diary has been found to compare favourably with seven day weighed records, with no significant differences in average food or nutrient intakes being apparent between the two methods. ${ }^{43}$

The conversion of data from the diaries into nutrient values was performed using COMPEAT 4 nutritional analysis system, ${ }^{44}$ based on the food composition data of the Nutrient Databank (Royal Society of Chemistry/Crown copyright material). ${ }^{45-50}$ Additional data on the nutritional compositions of fortified and prepared foods were obtained from retailers and manufacturers. Food portion sizes were assigned using relevant information provided in the diaries, standard food portion sizes, ${ }^{51}$ and manufacturers' information. A database of nutrient supplement compositions was compiled using manufacturers' information, and each subject's mean daily intake of nutrients from supplements was computed.

DATA MANAGEMENT AND STATISTICAL METHODS All data were entered using double key verification on SPSS Data Entry II. ${ }^{52}$ Statistical analysis was undertaken using SPSS for Windows. ${ }^{53}$ Sociodemographic variables examined were: smoking status; self reported number of cigarettes per day; maternal age at booking; maternal weight $(\mathrm{kg})$ at booking; reported maternal weight before conception; reported dieting before conception; maternal height $(\mathrm{m})$; body mass index (BMI) at booking (weight/height ${ }^{2}$ ); preconceptional BMI; diastolic blood pressure at booking; gestational age at booking in days (best estimates from last menstrual period and ultrasound data); social class in three groups (I and II; IIINM; and IIIM, IV, $\mathrm{V}$ ); education in three groups (above $\mathrm{O}$ level equivalent; $\mathrm{O}$ level equivalent; less than $\mathrm{O}$ level equivalent); and season in which food diary was completed. The data were first examined using univariate analyses. Comparisons between means were made using $t$ tests (after transforming non-normal data where necessary), and between proportions using $\chi^{2}$ tests. For non-normally distributed data with small group sizes, the Mann-Whitney U test (for two groups) and the Kruskall-Wallis test (for more than two groups) were used. Tests of significance were two tailed.

The associations between dietary intakes, smoking, and other sociodemographic factors were further examined using multiple linear regression. Smoking status was included in all the regression models. Other variables were considered if, in univariate analyses, they were significantly associated $(\mathrm{p}<0.05)$ with nutrient intake or smoking status, or if their association with dietary intake had been reported by others (for example, education and social class). Each model was built using a combination of forced entry and forward stepwise procedures: where the latter was used, the criterion for entry was $\mathrm{p}<0.05$ and for removal $\mathrm{p}>0.10$. Nutrient intakes that were markedly non-normal were suitably transformed (using logarithms or square roots: see table 3 ), and the fit of the model ascertained by examination of residuals. The associations between nutrient supplement use and predictor variables, including smoking, were examined using similar preliminary analyses and stepwise logistic regression. The significance of each predictor variable was generally assessed by the likelihood ratio test, but for forward stepwise entry, the Score test was used.

\section{Results}

Nine hundred and sixty three women agreed to participate in the study and all completed the structured interview at the antenatal clinic. Seven hundred and seventy four $(80.4 \%)$ of these subjects returned completed food diaries (referred to as "respondents"). Full details of the characteristics of respondents and nonrespondents have been given elsewhere. ${ }^{35}$ The respondents' social class distribution was comparable to that of a nationally representative 
Table 1 Characteristics of the 774 respondents by smoking status (mean (SD) or percentage $(n))$

\begin{tabular}{|c|c|c|c|}
\hline & $\begin{array}{l}\text { Non-smokers } \\
(n=461)\end{array}$ & $\begin{array}{l}\text { Smokers } \\
(n=313)\end{array}$ & $\begin{array}{l}p \text { Value of } \\
\text { difference }\end{array}$ \\
\hline & & Mean (SD) & \\
\hline Age $(y)$ & $26.6(4.6)$ & $24.5(5.2)$ & $<0.001$ \\
\hline Height $(\mathrm{cm})^{\star}$ & $164.3(6.3)$ & $164.3(6.7)$ & 0.936 \\
\hline Weight before pregnancy $(\mathrm{kg}) \dagger$ & $63.5(13.3)$ & $61.4(11.9)$ & 0.032 \\
\hline Weight at time of interview (kg) $\ddagger$ & $67.3(12.7)$ & $65.7(11.6)$ & 0.080 \\
\hline Body mass index at interview $\left(\mathrm{kg} / \mathrm{m}^{2}\right)$ & $24.9(4.3)$ & $24.3(4.1)$ & 0.064 \\
\hline Diastolic blood pressure at interview $(\mathrm{mm} \mathrm{Hg}) \int$ & $66 \quad(8)$ & $65 \quad(9)$ & 0.007 \\
\hline Gestational age at booking (weeks) & $16.3(1.3)$ & $16.4(1.4)$ & 0.309 \\
\hline Social class $\|$ & & $\% \quad(n)$ & \\
\hline I and II & $39.5(182)$ & $26.2(82)$ & $<0.0001$ \\
\hline IIINM & $34.9(161)$ & $32.3(101)$ & \\
\hline IIIM & $17.1(79)$ & $19.5(61)$ & \\
\hline IV and $\mathrm{V}$ & $5.9(27)$ & $18.8(59)$ & \\
\hline Unemployed/student/caring for home & $2.6(12)$ & $3.2(10)$ & \\
\hline \multicolumn{4}{|l|}{ Education } \\
\hline No qualifications & $2.8(13)$ & $13.1(41)$ & $<0.0001$ \\
\hline Up to CSE equivalent & $10.6(49)$ & $18.5(58)$ & \\
\hline Up to $\mathrm{O}$ level equivalent & $53.1(245)$ & $52.4(164)$ & \\
\hline Up to A level equivalent & $8.5(39)$ & $4.8(15)$ & \\
\hline Up to further education & $16.1(74)$ & $7.7(24)$ & \\
\hline Up to degree or higher & $8.9(41)$ & $3.5(11)$ & \\
\hline
\end{tabular}

${ }^{\star}$ Height unknown for one mother. $\$ 32$ mothers could not recall their weight before pregnancy. $\ddagger$ Weight at booking unknown for 22 mothers. §Blood pressure not recorded for 9 women. $\|$ Test performed across classes I to $\mathrm{V}$.

sample of mothers (all parities) in England and Wales, which defined social class by the woman's own occupation. ${ }^{54}$ Respondents were older than non-respondents (mean difference 2.3 years; $95 \%$ CI $1.5,3.1$ ). They were also better educated (26\% $v 16 \%$ had above O level qualifications; $\left.\chi^{2}=8.5, \mathrm{p}=0.004\right)$, and of higher socioeconomic class $(34 \% v 26 \%$ in classes I and II; $\left.\chi^{2}=4.3, p=0.04\right)$. Smokers were significantly less likely to return the food diary than were non-smokers $\left(74 \% v 85 \%, \chi^{2}=18.7\right.$, $\mathrm{p}<0.001)$. Nevertheless, no differences were seen between respondents and nonrespondents in height, weight before pregnancy, weight at booking, BMI before pregnancy, BMI at booking, or duration of pregnancy at booking. ${ }^{35}$ There were also no differences between respondents and nonrespondents in the following lifestyle related characteristics: dieting before conception $\left(18.1 \%\right.$ v $\left.18.5 \% ; \chi^{2}=0.19, \mathrm{p}=0.89\right)$; regular use of over the counter pain killers in pregnancy (53.4\% $v 60.3 \%, \chi^{2}=3.0 \mathrm{p}=0.09$ ); and haemoglobin concentration at booking $(12.2 \mathrm{~g} / \mathrm{dl}$ (SD

Table 2 Mean (SD) nutrient intakes from food of smokers and non-smokers

\begin{tabular}{|c|c|c|c|c|c|c|}
\hline & \multicolumn{4}{|c|}{ Mean (SD) } & \multirow[b]{2}{*}{$\begin{array}{l}\text { Difference between } \\
\text { means }(95 \% \text { CI) }\end{array}$} & \multirow[b]{2}{*}{$\begin{array}{l}p \text { Value of } \\
\text { difference }\end{array}$} \\
\hline & $\begin{array}{l}\text { Non-smol } \\
(n=461)\end{array}$ & kers & $\begin{array}{l}\text { Smokers } \\
(n=313)\end{array}$ & & & \\
\hline Energy (MJ) & 8.59 & $(1.7)$ & 8.49 & $(1.9)$ & $0.10(-0.16,0.36)$ & 0.447 \\
\hline Total fat (g) & 85.3 & $(22.1)$ & 86.3 & $(24.6)$ & $-1.0 \quad(-4.3,2.3)$ & 0.555 \\
\hline Protein $(\mathrm{g})$ & 75.0 & $(16.6)$ & 71.4 & $(18.2)$ & $3.6(1.1,6.1)$ & 0.004 \\
\hline Carbohydrate (g) & 257.5 & $(55.8)$ & 252.8 & $(59.4)$ & $4.7 \quad(-3.5,12.9)$ & 0.263 \\
\hline Fibre (g) & 18.2 & $(5.4)$ & 17.1 & $(4.8)$ & $1.1(0.4,1.9)$ & 0.003 \\
\hline Vitamin C (mg) & 90.7 & $(47.4)$ & 72.3 & $(47.6)$ & $18.4 \quad(11.6,25.2)$ & $<0.001$ \\
\hline Vitamin E (mg) & 9.3 & $(4.4)$ & 8.7 & $(4.4)$ & $0.6(0.0,1.2)$ & 0.063 \\
\hline Beta-carotene $(\mu \mathrm{g})$ & 1168 & $(890)$ & 937 & $(789)$ & $231 \quad(109,354)$ & $<0.001$ \\
\hline Total carotenoids $(\mu \mathrm{g})$ & 1843 & (1125) & 1323 & (999) & $(365,675)$ & $<0.001$ \\
\hline Retinol (ug) & 428.3 & (183.4) & 450.1 & $(336.9)$ & $-21.8 \quad(-58.7,15.1)$ & 0.245 \\
\hline Vitamin D $(\mu \mathrm{g})$ & 2.6 & (1.4) & 2.4 & (1.3) & $0.2 \quad(0.0,0.4)$ & 0.044 \\
\hline Thiamin (mg) & 1.58 & $(0.8)$ & 1.53 & $(1.4)$ & $0.05(-0.11,0.21)$ & 0.529 \\
\hline Folate $(\mu \mathrm{g})$ & 250.3 & $(73.8)$ & 230.3 & $(69.2)$ & $20.0 \quad(9.7,30.3)$ & $<0.001$ \\
\hline Vitamin B12 ( $\mu \mathrm{g})$ & 4.0 & $(1.6)$ & 3.8 & $(1.6)$ & $0.2(0.0,0.4)$ & 0.087 \\
\hline Iron $(\mathrm{mg})$ & 10.7 & (3.0) & 10.1 & (3.0) & $0.6 \quad(0.2,1.0)$ & 0.006 \\
\hline Zinc (mg) & 8.3 & $(2.2)$ & 7.9 & $(2.2)$ & $0.4 \quad(0.1,0.7)$ & 0.013 \\
\hline Calcium (mg) & 913.0 & $(275.4)$ & 898.9 & $(303.4)$ & $14.1 \quad(-27.2,55.4)$ & 0.503 \\
\hline Selenium $(\mu \mathrm{g})$ & 54.9 & $(22.2)$ & 51.4 & $(18.8)$ & $3.5(0.5,6.5)$ & 0.022 \\
\hline
\end{tabular}

${ }^{\star}$ By $t$ test.
1.0) $v 12.2 \mathrm{~g} / \mathrm{dl}$ (SD 0.9)). However, more non-responders reported exercising regularly (69\% of non-respondents $v 61 \%$ of respondents, $\left.\chi^{2}=5.1, \mathrm{p}=0.024\right)$. The outcome of pregnancy was also similar in both the 176 non-respondents and the 739 respondents delivering live, singleton infants in Portsmouth (birth weight $3.3 \mathrm{~kg}$ (SD 0.5) v $3.23 \mathrm{~kg}$ (SD $0.52), \mathrm{p}=0.13$; head circumference $34.8 \mathrm{~cm}$ $(\mathrm{SD} 1.4) \quad v 35.0 \mathrm{~cm} \quad(\mathrm{SD} 1.5), \mathrm{p}=0.32$; gestational age at delivery 39.8 weeks (SD 1.9) v 39.8 (SD 2.0), $\mathrm{p}=0.85$ ).

Among respondents, smokers were significantly younger than non-smokers, were of lower social class and education, and had slightly lower diastolic blood pressure at booking (table 1). They also reported weighing less before pregnancy than women who did not smoke, but their weight at booking, height and body mass index (BMI) were similar.

DIETARY INTAKE

Table 2 shows the crude dietary intakes of smokers and non-smokers. Smokers had lower intakes of most micronutrients. There were no significant differences between the intakes of light (1-12 cigarettes/day) and moderateheavy (13-45 cigarettes/day) smokers, nor did the diets of ex-smokers differ from those of non-smokers. Therefore subsequent results are presented for smokers and non-smokers only. Alteration of the cut off point for cotinine from 14 to $20 \mathrm{ng} / \mathrm{ml}$, or the inclusion of only those subjects with cotinine results that concurred with their self reported smoking status, made no important differences to the results.

Univariate analyses showed that a range of sociodemographic variables in addition to smoking were related to micronutrient intakes. In multiple regression analyses two variables, age and education, were consistently and significantly associated with dietary intake, after allowing for the effects of smoking. Height was also significantly and independently related to intakes of all nutrients except vitamin $\mathrm{C}$, vitamin $\mathrm{E}$ and iron, and was therefore included in all the models. BMI at booking was associated only with intakes of iron $(p<0.01)$, and pre-pregnant weight was an independent predictor of only folate $(p=0.01)$, iron $(\mathrm{p}=0.04)$ and vitamin B1 $(\mathrm{p}=0.01)$ intakes. For consistency, and because the results were not materially affected, BMI and pre-pregnant weight were not included in any model. No further variation in the consumption of any nutrient was explained by social class, current weight, pre-pregnancy dieting, gestational age at booking, systolic blood pressure, BMI before pregnancy, or season in which the food diary was completed. In contrast with the other micronutrients, vitamin $\mathrm{E}$ and $\mathrm{D}$ intakes were not found to be associated with any predictor variable except education.

Age had the strongest association with nutrient intake of any of the variables investigated. Table 3 shows the unadjusted intakes of all nutrients by age group (defined by approximate tertiles) and smoking status. After allowing for the effects of smoking, height and education, age alone explained $8.5 \%$ of the 
Table 3 Mean (SD) nutrient intakes from food observed among smokers (S) and non-smokers (NS) by age (split at approximate tertiles)

\begin{tabular}{|c|c|c|c|c|c|c|c|c|}
\hline & \multicolumn{6}{|c|}{ Age at booking $(y)$} & \multirow[b]{2}{*}{$\begin{array}{l}p \text { Value for } \\
\text { smoking }{ }^{\star}\end{array}$} & \multirow[b]{2}{*}{$\begin{array}{l}p \text { Value for } \\
\text { aget }\end{array}$} \\
\hline & $\begin{array}{l}<24 \\
N S(n=96)\end{array}$ & $S(n=134)$ & $\begin{array}{l}24-27 \\
N S(n=189)\end{array}$ & $S(n=97)$ & $\begin{array}{l}28 \text { and over } \\
N S(n=176)\end{array}$ & $S(n=82)$ & & \\
\hline Energy (MJ) & $8.3(1.9)$ & $8.4(2.0)$ & $8.5(1.8)$ & $8.4(1.8)$ & $8.8(1.7)$ & $9.0(2.0)$ & 0.670 & $<0.001$ \\
\hline Total fat (g) & $84.3(23.5)$ & $83.1(23.1)$ & $85.4(22.1)$ & $84.6(23.1)$ & $85.7(21.3)$ & $93.5(27.4)$ & 0.207 & 0.012 \\
\hline Protein $(\mathrm{g})$ & $68.3(16.0)$ & $66.1(17.4)$ & $74.9(16.9)$ & $71.1(17.0)$ & $77.7(15.7)$ & $81.1(17.5)$ & 0.523 & $<0.001$ \\
\hline Carbohydrate (g) & $257.5(55.9)$ & $248.4(65.4)$ & $252.9(56.0)$ & $254.2(55.7)$ & $262.3(55.5)$ & $258.4(53.2)$ & 0.925 & 0.130 \\
\hline Fibre $(\mathrm{g}) \ddagger$ & $16.4(4.1)$ & $15.8(4.6)$ & $17.7(5.4)$ & $17.2(4.2)$ & $19.6(5.8)$ & $18.9(5.3)$ & 0.380 & $<0.001$ \\
\hline Vitamin C $(\mathrm{mg}) \ddagger$ & $75.9(40.4)$ & $56.9(34.7)$ & $84.0(42.7)$ & $76.3(51.1)$ & $106.1(51.5)$ & $93.0(53.0)$ & $<0.001$ & $<0.001$ \\
\hline Vitamin E (mg) $\ddagger$ & $8.8(4.4)$ & $8.7(4.8)$ & $9.4(4.6)$ & $8.9(4.0)$ & $9.4(4.3)$ & $8.5(4.1)$ & 0.306 & 0.603 \\
\hline 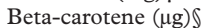 & $942 \quad(764)$ & $772 \quad(757)$ & $1050 \quad(700)$ & $976 \quad(728)$ & $1417 \quad(1066)$ & 1159 (857) & 0.033 & $<0.001$ \\
\hline Carotenoids $\ddagger(\mu \mathrm{g})$ & 1659 (987) & 1335 (982) & 1704 (989) & $1630 \quad(966)$ & 2093 (1283) & 1791 (1006) & 0.005 & $<0.001$ \\
\hline Retinol $(\mu \mathrm{g}) \ddagger$ & $405.7(176.4)$ & $417.1(244.3)$ & $416.2(182.9)$ & $402.4(139.1)$ & $453.5(185.7)$ & $560.5(547.1)$ & 0.073 & 0.002 \\
\hline Vitamin D $(\mu \mathrm{g}) \ddagger$ & $2.5(1.3)$ & $2.4(1.4)$ & $2.5(1.6)$ & $2.3(1.1)$ & $2.7(1.2)$ & $2.7(1.4)$ & 0.271 & 0.170 \\
\hline Thiamin (mg) $\ddagger$ & $1.5(0.8)$ & $1.3(0.4)$ & $1.6(0.9)$ & $1.8(2.5)$ & $1.7(0.6)$ & $1.6(0.4)$ & 0.437 & $<0.001$ \\
\hline Folate $(\mu \mathrm{g}) \ddagger$ & $220.1(61.1)$ & $209.3(58.8)$ & $240.5(70.6)$ & $229.0(63.4)$ & $277.2(74.8)$ & $266.2(77.3)$ & 0.286 & $<0.001$ \\
\hline Vitamin B12 $(\mu \mathrm{g})$ & $3.5(1.5)$ & $3.5(1.7)$ & $3.9(1.5)$ & $3.6(1.3)$ & $4.3(1.7)$ & $4.5(1.7)$ & 0.575 & $<0.001$ \\
\hline Iron (mg) $\ddagger$ & $9.3(2.1)$ & $9.1(2.4)$ & $10.5(3.0)$ & $10.0(2.8)$ & $11.7(3.0)$ & $11.9(3.3)$ & 0.574 & $<0.001$ \\
\hline Zinc (mg) $\ddagger$ & $7.2(1.9)$ & $7.2(2.2)$ & $8.3(2.1)$ & $7.9(2.0)$ & $8.9(2.1)$ & $9.0(2.1)$ & 0.987 & $<0.001$ \\
\hline Calcium (mg) $\ddagger$ & $874.4(270.3)$ & $815.5(278.9)$ & $900.5(275.2)$ & $878.0(251.8)$ & $1011.4(263.1)$ & $1060.0(336.9)$ & 0.835 & $<0.001$ \\
\hline Selenium $(\mu \mathrm{g}) \ddagger$ & $51.7(17.3)$ & $47.7(17.8)$ & $55.2(25.7)$ & $52.0(16.9)$ & $56.2(20.5)$ & $56.6(21.3)$ & 0.232 & 0.036 \\
\hline
\end{tabular}

*After adjusting for age, education and height. Height unknown for one mother. †After adjusting for smoking, education and height. Height unknown for one mother. $\ddagger$ Data log transformed for analysis. §Data square root transformed for analysis.

variation in iron intake, and was similarly important for most other nutrients. For most nutrients, intakes increased strikingly with age. For example, the regression equations indicate that after adjusting for other variables, intakes of vitamin $C$ rose by $16 \%(95 \%$ CI 11,21$)$ for every five year increase in maternal age, iron intakes increased by approximately 9\% (95\% CI 7,12$)$, and total carotenoids by $11 \%(95 \%$ CI 6, 16).

Maternal age remained strongly predictive of the intake of most nutrients $(\mathrm{p}<0.001)$ when simultaneous adjustment was made for total energy intake, in addition to maternal education, height and smoking. However, it was no longer a significant predictor of retinol or selenium intakes $(p=0.102, p=0.567)$ and there remained no association with vitamins $\mathrm{E}$ and D. The percentage of energy derived from protein was strongly associated with age $(p<0.001)$, but the percentage derived from fat or carbohydrate was not. After account had been taken of the influence of age, smoking remained a significant predictor of only the carotenoids and vitamin C.

NUTRIENT SUPPLEMENTATION

Many women obtained supplemental nutrients from more than one source. Furthermore, the use of supplements containing a variety of

Table 4 Observed percentages (n) of women using nutritional supplements by maternal age

\begin{tabular}{lccr}
\hline Nutrient & $\begin{array}{l}<24 y \\
(n=230)\end{array}$ & $\begin{array}{c}24-27 y \\
(n=286)\end{array}$ & $\begin{array}{l}28 y \text { and over } \\
(n=258)\end{array}$ \\
\hline Vitamin C & $5.2(12)$ & $7.3(21)$ & $14.0(36)$ \\
Vitamin E & $4.3(10)$ & $6.6(19)$ & $13.2(34)$ \\
Carotenoids & $3.0(7)$ & $2.8(8)$ & $3.9(10)$ \\
Retinol & $3.5(8)$ & $4.2(12)$ & $8.9(23)$ \\
Vitamin D & $5.2(12)$ & $7.7(22)$ & $15.9(41)$ \\
Thiamin & $4.3(10)$ & $7.0(20)$ & $13.2(34)$ \\
Folic Acid & $22.2(51)$ & $20.3(58)$ & $24.0(62)$ \\
Vitamin B12 & $3.9(9)$ & $7.0(20)$ & $11.2(29)$ \\
Iron & $14.8(34)$ & $13.3(38)$ & $13.2(34)$ \\
Zinc & $0.9(2)$ & $3.1(9)$ & $5.8(15)$ \\
Calcium & $2.6(6)$ & $3.1(9)$ & $7.0(18)$ \\
\hline
\end{tabular}

^No women consumed supplemental selenium. †For al nutrients except carotenoids, folic acid and iron, statistically significant association between age and supplement use in logistic regression using age as a continuous variable $(p<0.01$ in all cases). nutrients was common. Therefore for clarity the results are given separately for each nutrient and represent totals from all supplements.

In univariate analyses, a range of sociodemographic variables, including education and pre-pregnancy dieting, were associated with the use of nutrients. However, in logistic regression models, which were repeated for each nutrient, age was the only variable that was significantly associated with supplement use (though it was not associated with folic acid, iron, zinc or carotenoid supplementation). After allowing for the effects of age, the use of supplements was not associated with smoking, education, social class, height, weight or any other factor. Table 4 shows, for example, that the proportion of women using vitamin C supplements rose from 5\% among women aged less than 24 to $14 \%$ among those aged 28 and over, a difference of $9 \%(95 \%$ CI 4,14$)$. The use of vitamin $\mathrm{E}$ supplements showed a similar increase with age.

For those women taking supplements, these sources formed a high proportion of total dietary intake, and were greatest for vitamin $\mathrm{D}$, iron and folic acid. The mean proportions ranged from $23 \%(95 \%$ CI 17,30$)$ for calcium, to $57 \%(95 \%$ CI 55,59$)$ for folate, and $70 \%$ $(95 \%$ CI 66,75$)$ for iron. However, with the exception of folic acid and iron, most women did not use supplements (table 4). Thus for most nutrients, considering total nutrient intake (from diet and supplements) rather than intake from diet alone produced little change in the relations between intake, smoking, age and other sociodemographic factors. For iron and folate, in contrast, the relations of age and smoking to total intakes were much weaker than those to intake from food only, with age losing statistical significance $(p>0.05)$ as a predictor of intake for iron.

\section{Discussion}

We have investigated dietary intake during pregnancy in a large cohort of nulliparous smokers and non-smokers. By focusing on nulliparous women only, the study was able to 
investigate the importance of factors such as maternal age, which are strongly confounded by parity. The response rate was good, and we took care to evaluate the differences between respondents and non-respondents that could potentially limit the generalisability of the study. As with all observational studies, it is possible that our respondents differed in some unmeasured way from the general population, and this should be considered when interpreting the results. However, our data show that respondents and non-respondents were extremely similar in a wide variety of health related activities and in the outcome of pregnancy. There were some differences in response rate by smoking habit and age, but these differences would be likely to attenuate any relations rather than produce spurious results (smokers and young women who respond are likely to be more similar to non-smokers and older women than are non-respondents of equivalent age or smoking status).

The study was unusual in having sufficient statistical power to examine the intakes of smokers and non-smokers separately, and in using a biochemical marker of tobacco exposure in addition to self reports. Some women who were classified as smokers on the basis of serum cotinine, may not have been active smokers, but exposed to high levels of passive smoking. However, similar results were also obtained using only those women whose self reported smoking corresponded to their cotinine levels, or where more conservative approaches to reclassification were used. This suggests that "tobacco exposed" women, whether actively smoking or subject to heavy passive smoking, have dietary intakes that are distinct from women not exposed to tobacco. It can also be argued that whether or not derived from active smoking, high levels of tobacco components in the circulation are likely to have an important physiological impact.

Dietary intake was assessed at approximately 17 weeks gestation using seven day food diaries, which, unlike food frequency methods, give an acceptable measure of intake for most micronutrients. Detailed information on the consumption of nutrient supplements was also incorporated in the analysis. Nevertheless, some measurement error is inevitable, and care should be exercised in interpreting the results, particularly for selenium, as the Nutrient Databank is notably incomplete for this nutrient.

SMOKING AND NUTRIENT INTAKE

Smokers had poorer dietary intakes of most micronutrients than non-smokers. Although some antioxidants such as zinc were consumed in similar amounts by smokers and nonsmokers of comparable age and education, the apparently greater requirement for antioxidants among smokers means that their poor intakes may have greater biological implications.

For the carotenoids and vitamin $\mathrm{C}$, the effect of smoking was independent of other explanatory variables such as age, social class and edu-
KEY POINTS

- Pregnant smokers had poorer intakes of most micronutrients than did nonsmokers despite their greater requirements.

- Older women had higher intakes of most nutrients than did younger women of similar education, social class and smoking status.

- Intakes of supplementary nutrients increased with age, but were negatively associated with smoking for all nutrients except folic acid and iron.

- Young smokers are at risk of poor nutritional status during pregnancy and efforts should be made to increase their fruit and vegetable intakes.

cation. The risks to pregnancy from smoking may therefore be compounded by poor antioxidant intakes. Like other studies, vitamin $\mathrm{E}$ consumption was not associated with either smoking status or any other explanatory variable. However, unlike some previous reports, ${ }^{18} 2127$ smoking was not an independent predictor for a number of additional nutrients with antioxidant activity, including iron and zinc. This may be because the smokers in the other studies reported far higher levels of cigarette consumption than the women in our cohort, and therefore comparisons were made between more extreme groups; indeed Haste's work in pregnancy was designed specifically to compare heavy smokers and non-smokers. ${ }^{27}$ The social class distribution, and range of nutrient intakes observed in this cohort were comparable with representative samples of the non-pregnant population. ${ }^{35}$ It is therefore unlikely that important relations were overlooked because of a lack of baseline variability.

We were also unable to confirm earlier reports of trends in dietary intake with increasing cigarette consumption. The most probable explanation is that these patterns are masked in pregnancy as most women report reducing their cigarette consumption. A grouping such as "light smokers" is therefore likely to encompass a heterogeneous mixture of women including those were always light smokers, previous heavier smokers who have cut down, as well as women under-reporting their smoking intensity. Thus the group's nutrient intake is less likely to reflect their currently reported smoking intensity than would be the case for the general population. The relatively few women in the higher smoking intensity groups would also tend to obscure any relations with diet.

DIET AND AGE

We have found a strong trend of increasing dietary intake with maternal age for most antioxidants and other nutrients. These differences were attributable to both the greater total food intakes of older women, and also the higher nutrient densities of their diets. The importance of age in determining the diet of adults, whether pregnant or not, has previously 
been overlooked, possibly because of a lack of statistical power. In our study age was the single most important predictor of nutrient intake, and its effects were independent of other variables such as education and class. There are two possible explanations for this finding, and these may act synergistically. Firstly, the diets of young adults may be different from those of older people. Although most studies group all adults together for analysis, evidence from the most recent National Food Survey showed that intakes of fresh fruit and vegetables were over $25 \%$ lower in under 25 year olds compared with those aged 25-34. ${ }^{55}$ Secondly, women whose first pregnancy is delayed may differ from younger women of equivalent education and social class in a variety of health related activities. They may have had better diets than the younger women in the cohort when they were of similar age; and they are more likely to have planned the pregnancy or experienced delay in becoming pregnant, and may therefore be more motivated to change to a "healthier diet" on becoming pregnant. The data on preconceptional nutrient intakes collected from this cohort (using food frequency methods) will help to indicate whether the diets of older and younger women prior to pregnancy were comparable.

Consideration must be given to nutrient supplementation as total intakes may be of more biological significance than intakes from food alone. The relations of age and smoking to nutrient supplement use and to total nutrient intake (from food and supplements) varied in this cohort according to supplement type. For most nutrients, the use of supplements was consistent with the trends seen for diet, and, as would be expected, the relations between age, smoking habit and total intakes were unchanged, or became more striking compared with intakes from food only.

However, this was not true for total iron and folate intakes. A high proportion of the cohort took iron and folate supplements, and their use was similar in all groups of women: any underlying differences in diet therefore probably had little impact on total iron and folate consumption. Unfortunately it was not possible to determine whether all women complied equally with prescribed iron and folic acid supplements, or whether young women, smokers and those of lower education received more advice to take supplements (poor haematological profiles would be expected, given their low dietary iron intakes) but complied less well. It should be noted that the frequency of folic acid use reported in food diaries should not be taken to reflect intakes in the peri-conceptional period, as many women had already stopped taking the supplements: additional data for this time period are presented elsewhere. ${ }^{56}$ There was no trend in supplemental carotenoid intake with age. Carotenoids were largely obtained from multivitamin preparations designed for pregnancy (where carotenoids replaced retinol), and the women's choice of brand was unlikely to have been determined by whether the product contained carotenoids or excluded retinol. Zinc use also did not vary with age, possibly because few women used the supplement.

\section{CLINICAL IMPLICATIONS}

Our study has identified young women, particularly those who smoke, as being at risk of poor intakes of antioxidants and other nutrients during pregnancy. Given that the prevalence of smoking among young women is falling very slowly, if at all, and that pregnant smokers tend to be younger than non-smokers, these findings are cause for concern. However, young nulliparous women tend routinely to have greater contact with maternity services than do other groups, and it is encouraging that their use of iron and folate supplements is comparable with that of older non-smokers. Nulliparous women in general may also be more open to advice about their health behaviour during pregnancy. It is therefore possible that specific advice about diet, offered alongside current recommendations on food safety and the use of folic acid, may be well received.

However, care should be exercised before advising the use of antioxidant supplements: "antioxidants" can have pro-oxidant activity under certain conditions, and supplements have sometimes been associated with adverse outcomes (for example in cancer prevention trials). ${ }^{57} 58$ Moreover, there is currently no evidence that antioxidant supplementation in normal pregnancies is beneficial. ${ }^{30}$ In contrast, encouragement to eat five portions of fruit and vegetables per day may not only help ensure that poor diet does not exacerbate the effects of smoking in pregnancy, but may also provide the basis for long term dietary improvements in young women. Further analysis of this study is now being conducted to explore relations of nutritional intakes to the outcome of pregnancy.

Thanks are due to Mr J Bevan and colleagues for permission to include their patients in the study; the midwifery and support staff at St Mary's Hospital Portsmouth for their assistance; Linda Willis and Lin McRoberts for help in data collection and management; Tim Key and colleagues for permission to base the food diary on that used in the EPIC study; and all the women who participated in the research.

Funding: The Sir Jules Thorn Charitable Trust and Oxford University Medical Research Fund.

Conflicts of interest: none.

1 Rush D, Cassano P. Relationship of cigarette smoking and social class to birth weight and perinatal mortality among all births in Britain, 5-11 April, 1970. f Epidemiol Community Health 1983;37:249-55.

2 Butler N, Alberman E. Perinatal problems. The Second Report of the British Perinatal Mortality Survey. Edinburgh: Churchill Livingstone, 1969

3 Wisborg K, Henriksen TB, Hedegaard M, et al. Smoking during pregnancy and preterm birth. Br f Obstet Gynaecol 1996:103:800-5.

4 Galbraith RS, Karchmar EJ, Piercy WN, et al. The clinical prediction of intrauterine growth retardation. Am $\mathcal{F}$ Obstet Gynecol 1979:135:281-6.

5 U S Department of Health, Education and Welfare. Smoking and health. A report of the Surgeon General. Washington DC: US Govt Printing Office, 1979

6 Persson PH, Grennert L, Gennser G. A study of smoking and pregnancy with special respect to fetal growth. Acta Obstet Gynecol Scand (suppl) 1987;33:78.

7 Scott A, Moar V, Ounsted E. The relative contributions of different maternal factors in small-for-gestational age pregnancies. Eur f Obstet Gynecol Reprod Biol 1981;12:157-65.

8 White A, Freeth S, O'Brien M. Infant feeding. OPCS. London: HMSO, 1990.

9 Bolling K, Owen L. Smoking and pregnancy. A survey of knowledge, attitudes and behaviour. London: HEA, 1997. 
10 Foster K, Lader D, Cheesbrough S. Infant feeding 1995. ONS. London: HMSO, 1997.

11 Lumley J. Stopping smoking - again. Br f Obstet Gynaecol 1991:98:847-9.

12 Law M, Tang JL. An analysis of the effectiveness of interventions intended to help people stop smoking. Arch Intern Med 1995;155:1933-41.

13 Health Education Authority. Smoking and pregnancy: guidance for purchasers and providers. London: HEA, 1994

14 Office of Population Censuses and Surveys. Living in Britain: Results from the 1994 General Household Survey. London: HMSO, 1996.

15 Thomas M, Holroyd S, Goddard E. Smoking among secondary school children in 1992. London: HMSO, 1992.

16 Pelletier O. Vitamin C status of cigarette smokers and nonsmokers. Am f Clin Nutr 1970;23:520-4.

17 Gregory J, Foster $\mathrm{K}$, Tyler $\mathrm{H}$, et al. The dietary and nutritional survey of British adults. London: HMSO, 1990.

18 Margetts BM, Jackson AA. Interactions between people's diet and their smoking habits: the dietary and nutritional diet and their smoking habits: the dietary and

19 Bolton-Smith C, Casey CE, Gey KF, et al. Antioxidant vitamin intakes assessed using a food-frequency questionnaire: correlation with biochemical status in smokers and non-smokers. Br f Nutr 1991;65:337-46.

20 Cade J, Margetts BM. The relationship between diet and smoking: is the diet of smokers different? F Epidemiol Community Health 1991;45:270-2.

21 Zondervan KT, Ocke MC, Smit HA, et al. Do dietary and supplementary intakes of antioxidants differ with smoking status? Int 7 Epidemiol 1996;25:70-9.

22 Fehily A, Phillips KM, Yarnell JWG. Diet, smoking, social class, and body mass index in the Caerphilly Heart Disease Study. Am F Clin Nutr 1984;40:827-33.

23 Jarvinen R, Knekt P, Seppanen R, et al. Antioxidant vitamins in the diet: relationships with other personal characteristics in the diet: relationships with other personal characteristics

24 Woodward M, Bolton-Smith C, Tunstall-Pedoe H. Deficient health knowledge, diet and other lifestyles in smokers: is a multifa $354-61$.

25 Larkin FA, Badiotis P, Riddick HA, et al. Dietary patterns of women smokers and non-smokers. I Am Diet Assoc 1990;90:230-7.

26 Halliwell B. Cigarette smoking and health: a radical view. $\mathcal{F}$ $R$ Soc Health 1993;113:91-6.

27 Haste FM, Brooke O, Anderson HR, et al. Nutrient intakes during pregnancy: observations on the influence of smoking and social class. Am f Clin Nutr 1990;51:29-36.

28 Frisancho AR, Matos J, Leonard WR, et al. Developmental and nutritional determinants of pregnancy outcome among teenagers. Am f Phys Anthropol 1985;51:790-3.

29 Scholl TO, Hediger ML, Ances IG. Maternal growth during pregnancy and decreased infant birth weight. Am f Clin Nutr 1990;51:790-3.

30 Mathews F. Antioxidant nutrients in pregnancy: a systematic review of the literature. Nutrition Research Reviews atic review of

31 MRC Vitamin Study Research Group. Prevention of neural tube defects: results of the Medical Research Council Vitatube defects: results of the Medical Research
min Study Group. Lancet 1991;346:393-6.

32 Haste FM, Brooke OG, Anderson HR, et al. The effect of nutritional intake on outcome of pregnancy in smokers and non-smokers. Br f Nutr 1991;65:347-54.

33 Barker, DJP. The fetal origins of adult disease. Fetal and Maternal Medicine Review 1994;6:71-80.

34 Cosgrove M, Davies DP. Poor diet in pregnancy may be a proxy for some other hostile influence on fetal growth. [Letter]. BMF 1996;312:1478-9.

35 Mathews F, Neil HAW. Nutrient intakes during pregnancy in a cohort of nulliparous women. I Hum Nutr Diet 1998;11:151-61
36 Office of Population Censuses and Surveys. Standard occupational classification. London: HMSO, 1990.

37 Knight CJ, Wylie P, Holman MS, et al. Improved I-125 radioimmunoassay for cotinine by selective removal of bridge antibodies. Clin Chem 1985;31:118-21.

38 Cummings SR, Richard RJ. Optimum cutoff points for biochemical validation of smoking status. Am f Public Health 1988;78:574-5.

39 Wagenknecht LE, Burke GL, Perkins LL, et al. Misclassification of smoking status in the CARDIA study: a comparison of self-report with serum cotinine levels. Am F Public Health 1992;82:33-6.

40 Jarvis MJ, Tunstall-Pedoe H, Feyerbend C, et al. Comparison of tests used to distinguish smokers from nonsmokers. Am F Public Health 1987;77:1435-8.

41 Haddow JE, Knight GJ, Palomaki GE, et al. Secondtrimester serum cotinine levels in nonsmokers in relation to birth weight. Am $\mathcal{F}$ Obstet Gynecol 1988;159:481-4.

42 Benowitz NL, Kuyt F, Jacob P, et al. Cotinine disposition and effects. Clin Pharmacol Ther 1983;34:604-11

43 Bingham SA, Gill C, Welch A, et al. Comparison of dietary assessment methods in nutritionalpidemiology: weighed records versus $24 \mathrm{~h}$ recalls, food frequency questionnaires and estimated-diet records. Br f Nutr 1994;72:619-43.

44 COMP-EAT 4. Nutrition systems. Carlson Bengson Consultants Ltd, 21, Craven Hill, London.

45 Holland B, Welch AA, Unwin ID, et al. McCance and Widdowson's The composition of foods. 5th ed. Cambridge: The Royal Society of Chemistry, 1991.

46 Chan W, Brown J, Buss H. Miscellaneous foods. Supplement to the fifth edition of McCance and Widdowson's the composition of foods. Cambridge: The Royal Society of Chemistry, 1994.

47 Chan W, Brown J, Lee SM, et al. Meat, poultry and game. Supplement to the fifth edition of McCance and Widdowson's the composition of foods. Cambridge: The Royal Society of Chemistry, 1995.

48 Holland B, Unwin ID, Buss DH. Fruit and nuts. Supplement to McCance and Widdowson's the composition of foods. 5th ed. Cambridge: The Royal Society of Chemistry, 1992.

49 Holland B, Welch AA, Buss DH. Vegetable dishes. Second supplement to McCance and Widdowson's The composition of foods. 5th ed. Cambridge: The Royal Society of Chemistry, 1992.

50 Holland B, Brown J, Buss DH. Fish and fish products. Third supplement to McCance and Widdowson's The composition of foods. 5th ed. Cambridge: The Royal Society of Chemistry, 1993

51 Crawley H. Food portion sizes. 2nd ed. London: HMSO,

52 SPSS Inc. SPSS data entry II. Chicago: SPSS Inc, 1987.

53 SPSS Inc. SPSS for Windows base system user's guide. Release 6.0. Chicago: SPSS Inc, 1993.

54 Botting B, Cooper J. Analysing fertility and infant mortality by mother's social class as defined by occupation - part II Popul Trends 1993;74:27-33.

55 Ministry of Agriculture, Fisheries and Food. National food survey 1994. London: HMSO, 1995.

56 Mathews F, Yudkin P, Neil HAW. Folates in the periconceptional period: are women getting enough? $\mathrm{Br} f$ Obstet Gynaecol 1998;105:954-9.

57 Omenn GS, Goodman GE, Thornquist MD, et al. The effects of a combination of beta carotene and vitamin $\mathrm{A}$ on lung cancer and cardiovascular disease. $N$ Engl $f \mathrm{Med}$ 1996;334:1150-5

58 Alpha Tocopherol and Beta Carotene Cancer Prevention Study Group. The effect of vitamin E and beta carotene supplements on the incidence of lung cancer and other cancers in male smokers. N Engl f Med 1994;330:1029-35. 